\title{
Visual facilitation of auditory localization in schoolchildren: A signal detection analysis*
}

\author{
BILL JONES† \\ University of Waterloo, Waterloo, Ontario, Canada
}

\begin{abstract}
Warren (1970) has claimed that there are visual facilitation effects on auditory localization in adults but not in children. He suggests that a "visual map" organizes spatial information and that considerable experience of correlated auditory and visual events is necessary before normal spatial perception is developed. In the present experiment, children in Grades 1, 4, and 7 had to identify the position, right or left, of a single tone either blindfolded or with their eyes open. Analysis of the proportion of area under the ROC curve (obtained using reaction times) in the respective conditions showed that Ss were more sensitive to auditory position when vision was available. Reaction time was also generally faster in the light. I argue that the increase in sensitivity in the light represents updating of auditory position memory by voluntary eye movement. In the dark, eye movements are subject to involuntary and unperceived drift, which would introduce noise into the eye control mechanism and hence into auditory spatial memory.
\end{abstract}

There is good evidence that stimulation in one modality will increase the probability that a signal in another modality will be detected or otherwise correctly perceived (see Loveless, Brebner, \& Hamilton, 1970). Recently, Warren (1970) has shown that adults can point to unseen auditory targets more accurately when their eyes are open than when they are closed. Since he could not demonstrate a comparable intersensory facilitation effect in schoolchildren, Warren argued that vision provides primary and essential reference points for the organization of spatial information, and that considerable experience of the constant conjunction of visual and auditory information is necessary before adults are able to use a "visual map" on which to fix auditory points.

The finding that there is no visual involvement in auditory localization by children is difficult to square with the demonstration by Gomulicki (1961) that congenitally blind children cannot fix the position of a sound with the same accuracy as sighted children wearing blindfolds. Further, there is evidence against the notion that auditory-visual connections depend upon experience. In fact, new-born babies can detect auditory-visual discrepancies (Aronson \& Rosenbloom, 1971), which makes it reasonable to assume that a single phenomenological space is given for auditory and visual judgments and that the reliable coordination of the two modalities is basic to the perceptual system. ${ }^{1}$ It is surprising, therefore, when visual effects on auditory spatial judgments are

*Thanks are extended to John Bain for helpful comment on a pilot study.

†Address for reprints: Bill Jones, Department of Psychology, Carleton University, Ottawa, Ontario, Canada. reported only for adults. Essentially, there are two steps in Warren's (1970) presentation of evidence. In the first place, he clearly showed that pointing to an auditory target was more accurate with vision in adults but not in children. Secondly, he described psychophysical evidence for adults that vision increased auditory spatial acuity per se, and here he did not make a comparison with children. There may, therefore, be an intersensory effect in children which is obscured by inaccuracies in pointing to the target.

In the present study, the ability of children to judge the position (right or left) of a single tone was compared with and without the use of sight. No pointing response was required, so that measurement was made of visual effects on auditory spatial acuity. Assessment of spatial sensitivity made use of signal detection concepts. It has been shown that the basic theory of signal detection (e.g., Green \& Swets, 1966) may be extended to recognition experiments (e.g., Haller \& Atkinson, 1967; Kinchla \& Allan, 1969) where an observer's ability to distinguish which of two possible stimuli has been presented on a specific trial depends primarily on his memory for the stimulus from previous trials. Assuming imperfect memory, the $S$ must make a statistical inference about the current signal based on some response criterion, a preset value of the discrepancy between present and previous signals.

The dependent variable in the present experiment was the proportion of area under a curve of receiver operating characteristics (ROC). On each trial, the S was presented with a single signal on the right or on the left. Half the Ss responded "Yes" or "No" to the question, "Was the signal on the right?" while the others gave the same response to the question, "Was 
the signal on the left?"; i.e., independence of signal and noise trials was gained by treating the stimulus on the fixed side as signal and the stimulus on the opposite side as noise. The proportion of area under the ROC curve-designated $\mathrm{P}(\mathrm{A})$-is a nonparametric index of sensitivity independent of response bias (Green \& Swets, 1966).

The usual methods of obtaining criterion ROC curves are probably inappropriate with children. It is doubtful whether children can manipulate costs and payoffs in any very systematic way, and a pilot study showed that they were unwilling or unable to use a rating scale. Almost invariably, children would say that they were confident even when their demeanor showed uncertainty. In the present experiments, reaction times for "yes" and "no" responses were used to obtain latency ROC curves, the assumption being that the latency function is related to the decision axis and decreases with distance from the criterion (see Pike, 1973, for a discussion). Norman and Wickelgren (1969) have shown that latency and confidence probabilities have a similar function, i.e., both may be taken as an indication of recognition memory strength.

\section{METHOD}

\begin{abstract}
Subjects
Twelve children in each of Grades 1, 4, and 7 were used as Ss. In Grade 1, the mean age was 6 years, 7 months (range: 6 years, 2 months to 6 years, 9 months), in Grade 4, 9 years 7 months (range: 9 years, 5 months to 9 years, 10 months), and in Grade 7,12 years, 4 months (range: 12 years, 0 months to 12 years, 7 months). All Ss had normal uncorrected hearing and vision and all could correctly name their right and left sides.
\end{abstract}

\begin{abstract}
Apparatus
The $S$ was seated in an adjustable chair, and his head was fixed in a band attached to the apparatus which fitted around the forehead and back of the hea. Above the S's head and hidden from his view, two beams extended a distance of $4 \mathrm{ft}$ and from each of which a small hearing-aid loudspeaker was suspended, one $3 \mathrm{deg}$ to the right, the other $3 \mathrm{deg}$ to the left of the midline of the S's head. On a panel in front of the $S$ were two buttons, one labeled "yes" and the other "no," attached to timers. When the $S$ was asked if the signal was on the right, the "yes" button was also on that side, and correspondingly when he was asked if the signal was on the left, the "yes" button was also on the left. Signals were presented and the experiment preprogrammed by means of a multichannel tape system.
\end{abstract}

\section{Procedure}

On each trial, a step input tone $(3,200 \mathrm{~Hz}), 0.7 \mathrm{sec}$ in duration, was presented on one side. The position right or left of the signal was varied randomly with the provision that right and left occur equally often.

Within each age group, six Ss were assigned randomly to taking the right as the fixed signal and six to taking the left as the fixed signal. No-vision and vision conditions were the main experimental within-Ss variable. They differed in that in the no-vision condition the $S$ was blindfolded in such a way as not to interfere with hearing, while in the vision condition the $S$ had his eyes open and was told to look in the direction of the sound.

Ss were tested on successive days in two sessions of about $1 \mathrm{~h}$. Each session consisted of 200 trials, with the within-Ss variable counterbalanced (ABBA) in blocks of 50 . Since right and left events occurred equally often, there were 100 signal and 100 noise trials for each of the vision and no-vision conditions.

\section{RESULTS}

Reaction-time distribution for "yes" and "no" responses were obtained for each $S$ in each condition. Latency ROC curves representing performance were obtained as a plot of hits (the proportion of correct "yes" responses) against false alarms (the proportion of incorrect "yes" responses) for each of the following latency areas: quick "yes" responses (i.e., responses with a reaction time equal to or less than one standard deviation below the mean of the distribution of "yes" responses); moderate "yes" responses (i.e., responses within one standard deviation either way of the mean "yes" response); slow "yes" and "no" responses (i.e., responses greater than or equal to one standard deviation above the mean of either distribution); moderate "no" responses (i.e., responses within one standard deviation either way of the mean of the "no" distribution); and quick "no" responses (i.e., responses equal to or less than one standard deviation below the mean of the "no" distribution). The procedure is consequently equivalent to treating quick responses as very confident and slow responses as uncertain. There may, in practice, be differences between criterion ROC curves and latency ROC curves if there is uncertainty due to error variance in the latencies. Pike (1973) notes that the criterion ROC curve would then form an upper bound above the latency-derived curve. In other words, the latency curve will tend to underestimate sensitivity. It will be assumed here that the effects of error variance in the latency distributions are comparable across conditions.

For each $S$ in each condition, a ROC curve was plotted on squared paper, and $\mathrm{P}(\mathrm{A})$ values (Table 1) were obtained simply by counting squares under the curve. Sample ROC curves are shown in Fig. 1. A 3 by 2 by 2 ANOVA of $P(A)$ values with grades and signal

Table 1

Mean P (A) Values for Each Age Group and Each Condition

\begin{tabular}{|c|c|c|c|c|c|c|c|c|c|c|c|c|}
\hline \multirow{3}{*}{$\begin{array}{c}\text { Signal } \\
\text { Position }\end{array}$} & \multicolumn{4}{|c|}{ Grade 1} & \multicolumn{4}{|c|}{ Grade 4} & \multicolumn{4}{|c|}{ Grade 7} \\
\hline & \multicolumn{2}{|c|}{ No Vision } & \multicolumn{2}{|c|}{ Vision } & \multicolumn{2}{|c|}{ No Vision } & \multicolumn{2}{|c|}{ Vision } & \multicolumn{2}{|c|}{ No Vision } & \multicolumn{2}{|c|}{ Vision } \\
\hline & $\mathbf{M}$ & SD & $\mathbf{M}$ & $\mathrm{SD}$ & M & SD & $\mathrm{M}$ & SD & $\mathbf{M}$ & SD & M & SD \\
\hline Right & .60 & .03 & .72 & .04 & .63 & .03 & .82 & .04 & .65 & .04 & .78 & .03 \\
\hline Left & .59 & .02 & .71 & .03 & .63 & .02 & .81 & .02 & .71 & .10 & .80 & .02 \\
\hline
\end{tabular}


Fig. 1. Sample ROC curves for each condition.
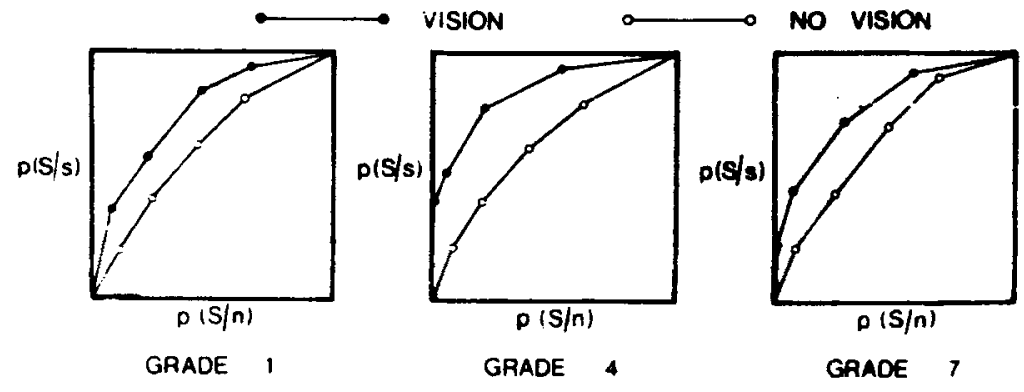

position ("yes"-right or "yes"-left) as between-S variables and no-vision/vision conditions as a within-Ss factor indicated significant main effects for both grades, $F=9.02$, $\mathrm{df}=2,30, \mathrm{p}<.001$, and no-vision/vision conditions, $F=80.15$, $\mathrm{df}=1,30$, $\mathrm{p}<.001$. There was no significant effect of signal position, $F=1.09$, df $=1,30$, and no significant interactions were found. The present results are, therefore, clearly contrary to Warren's (1970) hypothesis that the availability of vision does not facilitate auditory localization in children, since all age groups showed a significant increase in auditory spatial acuity when vision was present.

Interestingly, latencies (Table 2) also reflect a difference between no-vision and vision conditions. A 3 by 2 by 2 ANOVA of latency data with grades as a between-Ss factor and responses ("yes" or "no") and no-vision/vision conditions as within-Ss factors showed a significant effect of grades, $F=25.37$, df $=$ $2,33, \mathrm{p}<.001$, and of visual availability, $\mathrm{F}=9.05$, df $=1,33, \mathrm{p}<.001$. There was no significant difference in speed of "yes" and "no" responses, $F=1.00, \mathrm{df}=$ 1,33 , and no significant interactions were found.

\section{DISCUSSION}

Why should children (and adults) be more sensitive to the position of a tone in the light than in the dark? Norman and Wickelgren (1969) argue that latency represents memory trace strength and that shorter latencies reflect stable memory. Assuming that this is the case (though see Pike, 1973, who argues that latencies may reflect not distance from criterion but some stochastic count of observations for each binary response), the present results show that auditory position memory is more stable in the light.

Kinchla and Allan (1969) have described a model for how one may compare the position of two points of light seen successively in the dark. The index of sensitivity in their model- - , equivalent to $P(A)$ in the present experiment-is basically a measure of involuntary eye drift in the dark, i.e., a measure of how well the observer can retain spatial information in the absence of visual input. Platt and Warren (1972) have shown that Ss make eye movements toward auditory targets and that if the $S$ maintains a constant fixation, he localizes an auditory target with no more accuracy than in the dark. Eye movements, presumably controlled through central monitoring of efferent commands to the eye muscles (see, e.g., Festinger \& Canon, 1965), may therefore provide an additional representation of auditory position, and could thus update auditory position memory. Any "noise" in the eye-movement system would also affect memory for spatial position. Since the primary component of this "noise" is involuntary eye drift (Kinchla \& Allan, 1969), which Ss in the dark cannot detect (Matin, Pearce, Matin, \& Kibler, 1966), "noisier" eye movements are inevitable without visual input, and auditory position memory must, therefore, be less stable. The importance of a textured visual environment for auditory space perception (Platt \& Warren, 1972) is not only that of providing background targets for saccadic eye movements, but also of suppressing eye drift.

The eye-movement memory hypothesis, which is necessarily speculative in the present case, since eye movements were not monitored, turns, unlike that of Warren (1970), upon the control of eye movements rather than the development with experience of a correlation between visual and auditory inputs. Given a single auditory-visual space, the child simply has to learn to accurately align his eyes with the auditory target, and there is evidence from Wertheimer's (1961) study that this ability is at least grossly accurate at birth. (See Jones, 1972, and Kinchla \&

Table 2

Mean Latencies and Standard Deviations (in Seconds) for Each Response in Each Condition

\begin{tabular}{|c|c|c|c|c|c|c|c|c|}
\hline \multirow[b]{3}{*}{ Grade } & \multicolumn{4}{|c|}{ No Vision } & \multicolumn{4}{|c|}{ Vision } \\
\hline & \multicolumn{2}{|c|}{ "Yes" Response } & \multicolumn{2}{|c|}{ "No" Response } & \multicolumn{2}{|c|}{ "Yes" Response } & \multicolumn{2}{|c|}{ "No" Response } \\
\hline & $\mathbf{M}$ & SD & $\mathbf{M}$ & SD & $\mathbf{M}$ & SD & $\mathbf{M}$ & SD \\
\hline $\begin{array}{l}1 \\
4 \\
7 \\
\end{array}$ & $\begin{array}{l}3.01 \\
2.46 \\
2.18 \\
\end{array}$ & $\begin{array}{l}.59 \\
.81 \\
.36 \\
\end{array}$ & $\begin{array}{l}3.18 \\
2.60 \\
2.09 \\
\end{array}$ & $\begin{array}{l}.68 \\
.47 \\
.14 \\
\end{array}$ & $\begin{array}{l}2.98 \\
2.57 \\
2.01\end{array}$ & $\begin{array}{l}.42 \\
.37 \\
.15 \\
\end{array}$ & $\begin{array}{l}2.75 \\
2.47 \\
1.98\end{array}$ & $\begin{array}{l}.44 \\
.33 \\
.18\end{array}$ \\
\hline
\end{tabular}


Allan, 1969, for comparable reports on the facilitation of visual perception by movement.) Fishman and Michael (1973) have shown that there are cells in the so-called visual cortex of the cat which have coincident acoustic and visual receptive fields. They argue that such cells could play a part in the spatial localization of both auditory and visual stimuli. Cortical information could be transmitted to the oculomotor nuclei and the appropriate target-directed eye or head movements initiated. In other words, the relationship between auditory, visual, and movement cues in spatial perception may be a reciprocal one rather than vision's providing the primary map.

\section{REFERENCES}

Aronson, E., \& Rosenbloom, S. Space perception in early infancy: Perception within a common auditory-visual space. Science. 1971, 172. 1161-1163.

Festinger, L., \& Cannon, L. K. Information about spatial location based on knowledge about efference. Psychological Review, $1965,72,373-384$.

Fishman, M. C., \& Michael, C. R. Integration of auditory information in the cat's visual cortex. Vision Research, 1973, 13, 1415-1419.

Gomvlicki, B. R. The development of perception and learning in blind children. Private publication from the Psychological Laboratory, Cambridge University, 1961.

Green, D. M., \& Swets, J. A. Signal detection theory and psychophysics. New York: Wiley, 1966.

Haller, R. W., \& Atkinson, R. C. A memory-detection model for signal recognition. Institute for Mathematical Studies in the Social Sciences, Stanford University, Technical Report No. 110, 1967.
JoNEs, B. Facilitation of visual perception through voluntary movement in elementary schoolchildren. Journal of Experimental Child Psychology, 1972, 14, 408-416.

Kinchla, R. A., \& AllaN. L. G, A theory of visual movement perception. Psychological Review. 1968, 76, 537.558.

Loveless, N. E., Brebner, J., \& Hamilton, P. Bisensory presentation of information. Psychological Bulletin, 1970, 73, 161-199.

Matin, L., Pearce, D., Matin, E., \& Kibler, G. Visual perception of direction in the dark: Roles of local sign, eye movements and oculat proprioception. Vision Research, 1966, 6, 453-469.

Norman, D. A., \& Wickelgren, W. A. Strength theory of decision rules and latency in retrieval from short-term memory. Journal of Mathematical Psychology, 1969, 6, 192-208.

PIKE, R. Response latency models for signal detection. Psychological Review, 1973, 80, 53-68.

Plat, B. B., \& Warren, D. H. Auditory localization: The importance of eye movements and a textured visual environment. Perception \& Psychophysics, 1972, 12, 245-248.

WARREN, D. H. Intermodality interactions in spatial localization. Cognitive Psychology, 1970, 1, 144-153.

Wertheimer, M. Psychomotor co-ordination of auditory and visual space at birth. Science, 1961, 134, 1962.

\section{NOTE}

1. To say that a single space is given, does not argue for the "innateness" of auditory-visual space, since competence in the exercise of the concept of auditory-visual space could certainly be acquired through rather than from experience.

(Revision received for publication April 22. 1974; accepted April 29, 1974.) 